DOI: 10.17805/trudy.2017.1.8

\title{
ПРЕСТАРЕЛЫЕ ЛЮДИ \\ И ПСИХОЛОГИЧЕСКОЕ БЛАГОПОЛУЧИЕ \\ В СТАРЧЕСКОМ ВОЗРАСТЕ В СОЦИАЛЬНЫХ ПРЕДСТАВЛЕНИЯХ РАЗНЫХ ГРУПП ОБЩЕСТВА*
}

\author{
А. А. Зинина \\ Московский гуманитарный университет
}

Аннотация: В статье представлен анализ социальных представлений о престарелом человеке и его психологическом благополучии. Акцент сделан на атрибутировании ответственности за психологическое благополучие в старости.

Статья подготовлена на основе доклада автора на ХІІІ Международной научной конференции «Высшее образование для ХХІ века» (8-10 декабря 2016 г. в Московском гуманитарном университете).

Ключевые слова: социальные представления; престарелый возраст; психологическое благополучие; ответственность

\section{ELDERLY PEOPLE AND PSYCHOLOGICAL WELL-BEING IN OLD AGE IN SOCIAL PERCEPTIONS OF DIFFERENT GROUPS OF SOCIETY}

\author{
A. A. Zinina \\ Moscow University for the Humanities
}

Abstract: The article presents the research of social perceptions of elderly people and their psychological well-being. The research focuses on the topic of attribution of responsibility for the psychological well-being in old age.

The article is based on the author's presentation at the 13th International Scientific Conference «Higher Education for the 21st Century» (8-10 December 2016, Moscow University for the Humanities).

Keywords: social perceptions; old age; psychological well-being; responsibility

\footnotetext{
* Исследование выполнено при поддержке РГНФ (проект «Люди престарелого возраста в обыденном сознании студенческой молодежи и работающих взрослых: факторы ответственности», грант № 14-06-00434).

The research is supported by the Russian Foundation for the Humanities; grant № 14-06-00434 «Aged People in Mundane Consciousness of Student Youths and Working Adults: The Responsibility Factors».
} 
Исследование проблем старения считается одним из наиболее приоритетных направлений развития современной науки. Сегодня активно развивается медицина и геронтология; следствие чего увеличивается продолжительность жизни значительной части населения. Однако, для современной науки «особенно важно не прибавить годы к жизни; а прибавить жизнь к годам» (Толстых, 2004: 9). Именно поэтому все большую популярность приобретают исследования благополучного старения. Возрастные психологи и геронтологи подчеркивают сохранность личности стареющего индивида; а также отмечают возможности позднего периода жизни. Например; исследователи рассматривают старость как время духовного расцвета или акме (Бодалев, 1998); витаукт (Фролькис, 1988); эго-интеграцию (Эриксон, 1996); мудрость (Анцыферова, 2006); выделяют концепт счастливой старости (Шахматов, 1996) и успешного старения и др. Они показывают; что старческий возраст таит в себе ценные ресурсы; может предоставлять широкие возможности для достижения психологического благополучия личности (Ryff, 1996). Исследователи подчеркивают; что старость - это качественно новый и достаточно длительный этап жизни и развития человека.

Вместе с этим нельзя не замечать многочисленные проблемы престарелых людей: с одной стороны социальные - негативное общественное отношение к данной категории граждан; их отчуждение и дискриминация (Микляева, 2009; Елютина, 2010; Краснова, Лидерс, 2002; Смолькин, 2004; Никонова, 2007; Пряхина, 2006; Смирнова, 2008; Холостова, 2003 и др.); с другой - психологические: представители «третьего возраста» в большей степени ощущают себя ненужными обществу, одинокими, проигравшими и обиженными (Краснова, Лидерс; 2002; Толстых, 2004; Анцыферова, 2006; Глуханюк, Гершкович, 2003; Крайг, 2000). Можно сказать, что в современном обществе старческий возраст наделен «клеймом маргинального статуса» (Calasanti, 2008).

Важно отметить, что не только престарелые люди испытывают на себе влияние негативных общественных установок; представители более молодых возрастных групп культивируют страх перед поздними этапами жизни; что становится непреодолимым препятствием для достижения психологического благополучия. Т. В. Смирнова справедливо отмечает: «Нивелирование значения позднего периода жизни и нацеливание поколений на избежание старости влекут за собой неумение пожилых людей стариться; а молодых - адекватно воспринимать старость» (Смирнова, 2008: 50).

Осмысление старческого возраста с точки зрения социальной психологии является важной и перспективной задачей. В рамках исследования образ современных престарелых людей и благополучия в старости раскрывается путем анализа социальных представлений о данных феноме- 
нах. Важно подчеркнуть парадоксальный характер таких представлений (Jesuino, 2014). Парадоксальность представлений определяется тем фактом, что, с одной стороны в обществе превалируют преимущественно негативные установки по отношению к старческому возрасту, с другой - поздний возраст является неизбежным этапом онтогенеза каждого человека.

Процедура социально-психологического исследования включала два этапа. Первый преследовал цель изучить социальные представления (далее - СП) о престарелых людях. Для этой цели с помощью контентанализа эссе респондентов на поисковом этапе исследования была разработана шкала СП. В качестве респондентов выступали студенты $(\mathrm{N}=$ 70; 32 юношей и 38 девушек; средний возраст 19,4 года) и работающие взрослые ( $\mathrm{N}=70$; средний возраст 34,3, 28 мужчин и 42 женщины). На основании результатов первого этапа были сформированы цели и задачи второго, в ходе которого изучались СП о психологическом благополучии в старости; а особый акцент делался на исследовании тенденций при атрибутировании ответственности за психологическое благополучие. В качестве методов были использованы авторские шкалы для оценки структуры СП о психологическом благополучии в старости и атрибуции ответственности за психологическое благополучие. Выборку на данном этапе составили студенты ( $\mathrm{N}=80,47$ девушек, 33 юноши; средний возраст - 21,5 лет); работающие взрослые ( $=80 ; 60$ женщин; 20 мужчин; средний возраст - 37,3 лет) и неработающие пенсионеры $(\mathrm{N}=50,36$ женщин, 14 мужчин; средний возраст - 62,9 года). Перед заполнением анкеты респондентам пояснялось, что, согласно классификации Всемирной организации здравоохранения (ВО3), престарелыми считаются люди, достигшие 75-летнего возраста.

Математическая обработка осуществлялась в программе Statistica.10 и Statistica.13 с использованием коэффициента корреляции Спирмена и непараметрического критерия для несвязанных выборок Манна-Уитни; кластерного анализа по методу К-средних.

Центральным звеном исследования является изучение СП, их структуры и элементов в разных социальных группах. Структура СП включает ядерные и периферийные элементы, расчет которых производится путем математического подсчета коэффициента позитивных ответов - ТСР (Taux categorique positif); предложенного Ж.-К. Абриком (Емельянова, 2006: 243-244).

На первом этапе было обнаружено, что ядра СП в возрастных группах включают по четыре элемента, два из которых являются одинаковыми. Ядерными элементами СП в группе студентов являются «У престарелых людей появляется больше свободного времени» (коэффициент Абрика у студентов (далее С.) - 85, у работающих взрослых (далее - Р. В.) - 72), 
«Престарелые люди вызывают чувство уважения» (С. - 80; Р. В. - 70). Сходными элементами в группе студентов и работающих взрослых определены следующие: «У престарелых людей в России маленькие пенсии» (С. - 91, Р. В. - 95) и «Престарелым людям трудно привыкать к чему-то новому» (С. - 89, Р. В. - 80). В группе работающих взрослых ядро представлено следующими элементами: «За рубежом положение стариков лучше» (С. - 76, Р. В. - 88); «Престарелые люди получают крайне плохое социальное обслуживание» (С. - 67, Р. В. - 87). Можно сказать; что ядерные элементы в группе работающих взрослых отличаются общей негативной направленностью. В группе студентов в ядре СП появляются положительно и нейтрально окрашенные элементы. Периферия, близкая к ядру, в обеих группах состоит их одиннадцати элементов, семь из которых одинаковы. С одной стороны, группы подчеркивают, что «престарелые люди не имеют возможности содержать себя на должном уровне» (С. - 63, Р. В. - 64) и «их не ценят в обществе» (С. - 42, Р. В. - 38); с другой - отмечают, что «престарелые люди вызывают чувство уважения» (С. - 77, Р. В. - 73). Далекая от ядра представлений периферия состоит из семи элементов, пять из которых сходны. Респонденты не считают, что «престарелые люди ворчливы и всем недовольны» (С. - 67, Р. В. - 87); что «у них пропадает интерес к жизни» (С. - 30, Р. В. - 27) и что «пенсии стариков являются стабильным источником дохода для их детей и внуков» (С. - 9, Р. В. - 11).

В рамках работы эмпирическим путем были выделены значимые различия. Например; работающие взрослые считают; что престарелые люди мудрые и имеют богатый жизненный опыт (С. - 57, Р. В. - 69). Различия по этому элементу СП значимы $(\mathrm{p}<0,05)$. Студенты; в отличие от взрослых; склонны считать престарелых людей неспособными обойтись без посторонней помощи и нуждающимися в поддержке (С. - 53, Р. В. $23)$; больными и немощными (С. - 37, Р. В. - 22). Работающие взрослые чаще отмечают; что престарелых людей избегают в обществе и относятся к ним пренебрежительно (С. - 27, Р. В. - 56).

По результатам второго этапа исследования мы заключили, что в студенческой группе ядро СП о психологическом благополучии в старости образовано из 8 элементов; близкая к ядру периферия - из 14, удаленная от ядра периферия - также из 14. В группе работающих взрослых ядро состоит из 6 элементов, близкая к ядру периферия - из 17, а удаленная от ядра периферия - из 13. У неработающих пенсионеров в состав ядра входят 7 элементов, в близкую периферию - 15, в далекую - 14. Ядра СП в исследуемых группах включают четыре одинаковых элемента. Группы солидарны в том, что психологически благополучный престарелый человек находится в гармонии с собой и окружающим миром (С. -85 , Р. В. 89, Н. П. - 90); сам создает такую гармонию (С. - 89, Р. В. - 88, Н. П. - 86). 
Респонденты выделяют вклад внимания и заботы со стороны родных и близких в развитие психологического благополучия (С. -85 , Р. В. -89, Н. П. - 86); а также подчеркивают; что оно связано со здоровьем (С. -86 , Р. В. - 93; Н. П. - 94). Удаленная от ядра периферия имеет 9 общих элементов. Все респонденты не согласны с утверждением; что большинство престарелых людей психологически благополучны (С. - 15, Р. В. - 16, Н. П. - 44). Кроме этого, группы не отмечают существенной роли религиозности при формировании благополучия в старческом возрасте (С. -22 , Р. В. - 20, Н. П. - 30) и не выражают согласия с тем, что «смыслообразующим занятием для престарелого человека является помощь семье (уход за внуками; помощь по дому)» (С. - 55, Р. В. - 52, Н. П. - 60). Респонденты заключают, что ни путешествия (С. -35 , Р. В. -44 , Н. П. -54$)$; ни модная одежда (С. - 19, Р. В. - 26, Н. П. - 53); ни освоение современных технологий (С. - 34, Р. В. - 35, Н. П. - 54) не приближают престарелого человека к благополучию, а также отрицают, что в России и мире существует общий приоритет молодости; при котором престарелые люди не ценятся в обществе (С. - 48, Р. В. - 40, Н. П. - 46).

Вместе с этим, исследуемые группы в значительной степени отличаются друг от друга. Так, студенты, в отличие от респондентов других социальных групп ( $<<0,05)$, не согласны с утверждением, что для повышения психологического благополучия престарелых людей необходимо изменить общественное мнение (С. - 60, Р. В. - 81, Н. П. - 78). Кроме этого, студенты меньше других групп связывают благополучие в старости с активной культурной жизнью (С. - 44, Р. В. - 66, Н. П. - 72). Работающие взрослые особое внимание придают наличию цели и смысла жизни в контексте психологического благополучия (С. -66, Р. В. -85, Н. П. -80$)$. Данная группа в большей степени обеспокоена социальными проблемами. Ее представители отмечают, что для повышения благополучия престарелых людей необходимо изменить общественное отношение (С. - 60, Р. В. - 81, Н. П. - 778), а также подчеркивают, что престарелые люди часто не получают поддержку государства (С. - 80, Р. В. - 88, Н. П. - 70). Неработающие пенсионеры значимо отличаются от других социальных групп убежденностью в том, что благополучные в психологическом плане престарелые люди стараются ухаживать за собой (С. - 51, Р. В. - 66, Н. П. - 76). Именно неработающие пенсионеры подчеркивают, что благополучные престарелые не стараются навязать опыт молодому поколению (С. - 35, Р. В. - 42, Н. П. - 70).

При изучении атрибуции ответственности за психологическое благополучие в старческом возрасте были выявлены некоторые тенденции. Так, студенты утверждают, что «никто не может повлиять на психологическое благополучие престарелого человека, если он сам этого не захочет», а также отмечают меньшее участие общества при формировании 
психологического благополучия в старости (по этому параметру студенты значимо ( $<<0,001)$ отличаются от других групп). Работающие взрослые примерно в равной степени приписывают ответственность личностным особенностям престарелых людей, обществу и государству. Старшая возрастная группа - неработающие пенсионеры - предполагает, что преимущественно семья способна повлиять на благополучие престарелых людей. Более того, по мнению респондентов данной возрастной группы, личностный вклад престарелых людей в собственное благополучие сопоставим с вкладом государства.

Итак, подведем итоги исследования.

1. В рамках эмпирического исследования на первом этапе показано, что СП о престарелых людях различаются в социально-демографических группах. Студенты склонны считать престарелых людей неспособными обойтись без посторонней помощи и нуждающимися в поддержке, больными и немощными. Работающие взрослые чаще отмечают, что престарелые люди получают крайне плохое социальное обслуживание, что их избегают в обществе и относятся к ним пренебрежительно. Они также акцентируют внимание на том, что престарелые люди мудрые и имеют богатый жизненный опыт.

2. На втором этапе исследования определено, что респонденты разных групп в социальных представлениях о психологическом благополучии престарелых людей обращают внимание на здоровье, личностное отношение престарелых к процессу старения, позитивные отношения внутри семьи, а также на гармоничность отношений между психологически благополучным престарелым и окружающим его миром. Данные ядерные элементы социального представления отражают биологические, психологические и социальные аспекты благополучного старения.

3. В рамках работы также были обозначены значимые различия между исследуемыми группами: студенты подчеркивают значимость социальных контактов в старческом возрасте, работающие взрослые большое значение придают наличию целей в жизни, неработающие пенсионеры - деятельному образу жизни. Между элементами социального представления определяются группспецифичные корреляционные зависимости.

4. Ответственность за психологическое благополучие в старости оказалась многоликой: студенты и работающие взрослые приписывают ответственность за психологическое благополучие в престарелом возрасте личности престарелого человека. В то же время неработающие пенсионеры полагают, что в большей степени семья способна повлиять на благополучие в старости, а личностный вклад престарелых в собственное благополучие сравним с вкладом государства и общества. 
Изучение престарелых людей, их положения в обществе, а также психологического благополучия в старческом возрасте является актуальной проблемой в свете увеличения численности лиц позднего возраста. Общество стареет, и особую значимость приобретают вопросы, связанные с психологическим благополучием такого общества. Однако старость в современном мире только начинает осмысляться как новый длительный этап жизни и развития человека. К сожалению, в обыденном сознании современного российского общества широко представлены многочисленные проблемы престарелых: экономические, социальные и психологические. Кроме этого, в современном обществе престарелые люди становятся жертвами возрастной дискриминации или эйджизма. Однако главной особенностью этого явления, в отличие от сексизма и расизма, является то, что молодые люди, в конечном счете, станут престарелыми, следовательно, негативные возрастные предубеждения по отношению к последним рассматриваются молодыми как угрожающие собственному «Я». Молодые люди продуцируют негативное отношение к престарелым и осуждают последних за их состояние, общественное положение - атрибутируют ответственность за психологическое благополучие личности престарелого человека. Как замечает Т. Д. Нельсон, более молодые возрастные группы пытаются «сохранить иллюзию, что они не подвергнутся такому же процессу старения» (Нельсон, 2003: 255). Подобное отношение к престарелым людям способствует увеличению разрыва между поколениями, и, как следствие, потере культурного опыта (Мид, 1988). Общество крайне разобщено, а разные возрастные группы часто не понимают друг друга. Полученные результаты позволяют судить о неоднозначном восприятии психологического благополучия в старческом возрасте, что сказывается как на благополучии стариков, так и на благополучии других возрастных групп.

\section{СПИСОК ЛИТЕРАТУРЫ}

Анцыферова, Л. И. (2006) Развитие личности и проблемы геронтопсихологии. М. : Изд-во «Институт психологии РАН».

Бодалев, А. А. (1998) Вершина в развитии взрослого человека: характеристики и условия достижения. М. : Флинта ; Наука.

Глуханюк, Н. С., Гершкович, Н. С. (2003) Поздний возраст и стратегии его освоения. 2-е изд., доп. М. : Московский психолого-социальный институт.

Елютина, М. Э. (2010) Старость в современном российском обществе: интерсубъективный и интеробъективный контексты. Саратов: Сарат. гос. техн. ун-т. 
Емельянова, Т. П. (2006) Конструирование социальных представлений в условиях трансформации российского общества. М.: Издво «Институт психологии РАН».

Крайг, Г. (2000) Психология развития. СПб.: Питер.

Краснова, О. В., Лидерс, А. Г. (2002) Социальная психология старения: учеб. пособие для студ. высш. учеб. заведений. М.: Академия.

Мид, М. (1988) Культура и мир детства. М.: Наука.

Микляева, А. В. (2009) Возрастная дискриминация как социальнопсихологический феномен. СПб. : Речь.

Нельсон, Т. (2003) Психология предубеждений. Секреты шаблонов мышления, восприятия и поведения. СПб. : Прайм-ЕВРОЗНАК.

Никонова, Э. И. (2007) Место и роль пожилых людей в современном российском обществе // Вестник Нижегородского университета им. Н. И. Лобачевского. Серия «Социальные науки». № 3 (8). С. 76-81.

Пряхина, С. Б. (2006) Проблема эйджизма в современной России // Актуальные проблемы психологического знания: сб. науч. трудов. № 1 . C.95-121.

Смирнова, Т. В. (2008) Стереотипный образ и социальная дистанция // Социологические исследования. № 8. С. 49-55.

Смолькин, А. А. (2004) Социокультурная динамика отношения к старости: автореф... канд. соц. н. Саратов.

Толстых, А. (2004) На старости лет // Психология старости. Самара: Издательский дом БАРАХ-М. С. 3-33.

Фролькис, В. В. (1988) Старение и увеличение продолжительности жизни. Л. : Наука: Ленингр. Отд ние.

Холостова, Е. И. (2003) Социальная работа с пожилыми людьми: учеб. пособие. 2-е изд. М. : Издательско-торговая корпорация «Дашков и К».

Шахматов, Н. Ф. (1996) Психическое старение: счастливое и болезненное. М. : Медицина.

Эриксон, Э. Г. (1996) Детство и общество. 2-е изд.; перераб. и доп. СПб. : Ленато ; АСТ ; Фонд «Университетская книга».

Calasanti, T. (2008) A feminist confronts ageism// Journal of Aging Studies. V. 22. P. $152-157$.

Jesuino, J. C. (2014) Images of old age // Papers on Social Representations. V. 23. P. $15.1-15.22$.

Ryff, C. D. (1996) Psychological Well-Being // Encyclopedia of Gerontology, J. E. Birren (ed.). San Diego, CA: Academic Press. V. 2. P. 365-369. 
Зинина Анна Александровна - аспирант кафедры социальной и этнической психологии Московского гуманитарного университета. Адрес: 111395, Россия, г. Москва, ул. Юности, д. 5. Тел.: +7 (499) 374-56-11. Эл. адрес: anna.zinina.22@gmail.com. Научный руководитель - д-р психол.н., проф. Т. П. Емельянова.

Zinina Anna Aleksandrovna, Postgraduate Student, Department of Social and Ethnic Psychology, Moscow University for the Humanities. Postal address: 5, Yunosti St., Moscow, Russian Federation 111395. Tel.: +7 (499) 374-56-11. E-mail: anna.zinina.22@gmail.com. Scientific Adviser - T. P. Yemelianova, Doctor of Psychology, Professor.

\section{Для цитирования:}

Зинина А. А. Престарелые люди и психологическое благополучие в старческом возрасте в социальных представлениях разных групп общества [Электронный ресурс] // Научные труды Московского гуманитарного университета. 2017, № 1. URL: http:// journals.mosgu.ru/trudy/article/view/399 (дата обращения: дд.мм.гг.). DOI: 10.17805/ trudy.2017.1.8 